Research Article

\title{
Experimental Study on Grouting Effect and Mechanical Properties of the Rockfill Materials Grouted with SCM
}

\author{
Cheng-Jin Deng $\mathbb{D}^{1,2}$ Fa-Ning Dang $\mathbb{D}^{1},{ }^{1}$ Xing-Zhou Chen, ${ }^{3}$ Zhe Miao, ${ }^{2}$ and Li-Li Chen ${ }^{3}$ \\ ${ }^{1}$ Institute of Geotechnical Engineering, Xi'an University of Technology, 5 South Jinhua Road, Xi'an 710048, China \\ ${ }^{2}$ Northwest Engineering Corporation Limited, 18 Zhangba East Road, Xi'an 710065, China \\ ${ }^{3}$ Xi'an University of Science and Technology, 58 Yanta Road, Xi'an 710054, China \\ Correspondence should be addressed to Fa-Ning Dang; dangfn@mail.xaut.edu.cn
}

Received 4 July 2020; Revised 24 August 2020; Accepted 31 October 2020; Published 21 November 2020

Academic Editor: Xinyu Ye

Copyright (c) 2020 Cheng-Jin Deng et al. This is an open access article distributed under the Creative Commons Attribution License, which permits unrestricted use, distribution, and reproduction in any medium, provided the original work is properly cited.

\begin{abstract}
Insufficient compactness of rockfill materials may potentially cause excessive deformation of a concrete face rockfill dam (CFRD), thus resulting in cracking of the face slab and leakage of the dam body, thereby requiring reinforcement treatment. To date, there are no effective measures in strengthening rockfill materials. In this study, self-compacting mortar (SCM) was applied to the Shibaozhai CFRD in Gansu Province, China, to test the effectiveness of grouting reinforcement. Simultaneously, an indoor triaxial shear test was conducted to investigate the changes in the mechanical properties of rockfill materials before and after the grouting reinforcement. The on-site test results showed that the rockfill reached the desired porosity after grouting and grouting reinforcement enhanced the cementation degree of rockfill materials while maintaining uninterrupted drainage capacity, which met the requirements of rockfill grouting for the face rockfill dam. The results of the triaxial shear test indicated that the cohesive force of the rockfill materials rose by 3.95 times and the modulus increased by 7.24 times after grouting reinforcement, significantly enhancing the mechanical and deformation properties of the rockfill. An increase in the content of coarse particles was shown to enhance the stability of cementitious structures, which leads to a better skeleton effect and thereby raises the effectiveness of the grouting reinforcement. The rockfill materials also exhibited strain-softening characteristics following the grouting reinforcement. The research showed that grouting reinforcement technology is suitable for managing the deformation of high CFRDs or reinforcing ill rockfill dams.
\end{abstract}

\section{Introduction}

The mechanics and deformation characteristics of rockfill materials for concrete face rockfill dams (CFRDs) are dependent on the rockfill strength, the particles' gradation composition, and their compactness $[1,2]$. Therefore, the required particle size and compactness of the rockfill materials have been standardized, and the relevant research results have traditionally been used to form the theoretical basis for the deformation control of CFRDs. For high CFRDs, deformation control measures such as reducing the porosity of the rockfill and setting high modulus zone are widely used $[3,4]$. Despite this, some high CFRDs may still develop varying degrees of problems (e.g., cushion cracks, slab cracks, slab crushing and damage, slab separation, and serious leakage) due to inconsistent and large deformation of the dam body. This has been observed in several cases, such as China's Shuibuya dam (233 m high), Brazil's Barra Grande dam (185 m high), and the Campos Novos dam (202 m high) [5-8].

To manage the deformation of rockfill dams, researchers have investigated mixing rockfill materials with cementitious materials to upgrade the mechanical properties. The deformation capacity of the rockfill materials could be significantly enhanced through mixing, paving, rolling, and other processes [9]. However, incorporation of cementitious materials would vastly decrease the water permeability of cemented rockfill materials, and the mixing process of 
cementitious materials is not as convenient as the grouting process. Additionally, excessive deformation caused by insufficiently compacted rockfill materials after project completions is problematic to address $[10,11]$.

Experimental research on grouting reinforcement of the rock-soil body and postreinforcement has primarily been concentrated on the treatment of a fractured rock mass or clay [12-14]. Thus, researchers have used pressurized grouting to fill the pores or fissures of the rock-soil body with slurry, which needs to be diluted to achieve acceptable fluidity. In contrast, the rockfill materials of CFRDs have large porosity, so conventional grouting inevitably results in slurry leakage. Therefore, it is nearly impossible to manage the diffusion range, filling effect, and engineering quantity of the slurry. Overall, minimal attention has been given to the investigation of grouting reinforcement technology for improving the CFRD rockfill materials modulus, and there is no effective reinforcement treatment specific to such an application.

Self-compacting concrete (SCC) can fill narrow parts of pores under the action of its own weight to form a complete cement body. Related technology has been applied to rockfill concrete dams $[15,16]$. However, the design concepts of a rockfill concrete dam and CFRD are greatly different because the latter does not require all pores of the rockfill materials to be filled with the slurry. Grouting reinforcement of a CFRD is utilized not only to improve the ability of the rockfill to resist deformation, but also to maintain a certain degree of unhindered drainage capacity and to reduce the amount of grouting required. Thus, a selfcompacting mortar (SCM) with Bingham rheological properties is a suitable injection material [17], which can be applied to the high modulus zone of high CFRDs or the reinforcement of dams at risk.

In this study, the performance of SCM was investigated via employing it as a grouting material in an on-site grouting reinforcement test of the Shibaozhai CFRD in Gansu Province, China. A triaxial shear test was simultaneously performed on grout-reinforced rockfill materials to compare their mechanical properties before and after grouting. These findings should provide theoretical support for engineering applications of grouting reinforcement technology for CFRDs.

\section{Protocol for Grouting Reinforcement Test of the Shibaozhai CFRD}

The grouting test was performed on the Shibaozhai CFRD, which is on the Cedi River in Gansu Province, China (Figure 1). The dam is $44 \mathrm{~m}$ in height, and the main rockfill material is arkoses, which has a saturated compressive strength of $40.2 \mathrm{MPa}$. The distribution of the settlement and deformation of the dam top measured in the field is shown in Figure 2. The settlement and deformation of the dam top at the riverbed section with pile number $0+140$ was the greatest, which is approximately $1.12 \mathrm{~m}$ and accounts for $2.5 \%$ of the dam height. Because of the disorganized use of filling material, poor construction quality, and low degree of roller compaction, the deformation of the dam was so great that the slab developed structural cracks, and the slab joint seal was damaged with severe dam leakage.

A particle gradation test was conducted at the Shibaozhai CFRD; Figure 3 shows the experimental grading curve of the main rockfill materials. The distribution of the main rockfill materials in the particle size range of $30-300 \mathrm{~mm}$ was observed to be deviated from the design gradation envelope, which indicated that the main rockfill materials failed to meet the design requirements. The measured porosity in the main rockfill area was $30 \%$, which was much greater than the $20-25 \%$ required by the design specification. These results proved that the particle gradation and the low compactness of the roller-compacted rockfill materials were the main reasons for the low strength and large deformation of the rockfill materials, which ultimately caused excessive deformation of the dam body.

To study the grouting reinforcement effect of SCM on the rockfill materials of the CFRD, an on-site grouting reinforcement test was conducted, and the results were analyzed with a pit inspection, core drilling, density logging, in-hole TV camera, and water injection permeability test. A triaxial shear test was also performed with the test scheme shown in Figure 4 to analyze the mechanical properties of the rockfill materials before and after grouting reinforcement.

\section{On-site Grouting Reinforcement Test}

3.1. Field Test Process. The setup for the on-site grouting test is shown in Figure 5. The grouting holes were spaced at $2 \mathrm{~m}$, and the grouting effectiveness of SCM for rockfill materials was verified through a pit and drilling inspection. The European specification EFNARC uses the flow spread and $\mathrm{V}$-funnel time to evaluate the fluidity and cohesiveness of SCM [18]; it recommends a flow spread of $240 \pm 20 \mathrm{~mm}$ and $\mathrm{V}$-funnel time of 7-11 s. Because this rockfill dam had a high content of fine particles, the fluidity of the mortar needed to be enhanced. Thus, the on-site grouting test was conducted under the conditions of a water-to-binder ratio of 1.0, admixture content of $1 \%$, slump spread of $390 \mathrm{~mm}$, and $\mathrm{V}$-funnel time of $4.42 \mathrm{~s}$ for the SCM.

For the reinforcement of the rockfill materials, overburden drilling was conducted all the way to the bottom, and a perforated pipe was then inserted. This was then followed by removal of the casing and grouting with the SCM in a sectionby-section approach from bottom to up; each section was $2-5 \mathrm{~m}$ in length. The grouting amount of each section was calculated according to the diffusion range of SCM in order to achieve the porosity of $20 \%$. The prepared SCM was directly injected into the perforated pipe through a chute, a measuring tank, or a funnel without pressurization. The grout automatically flowed from pipe holes to the surrounding rockfill and filled some pores between the rockfill.

3.2. Inspection Results after Grouting. As shown in Figure 6, the pit inspection and core drilling inspection revealed obvious mortar cementation between large stones at a depth 


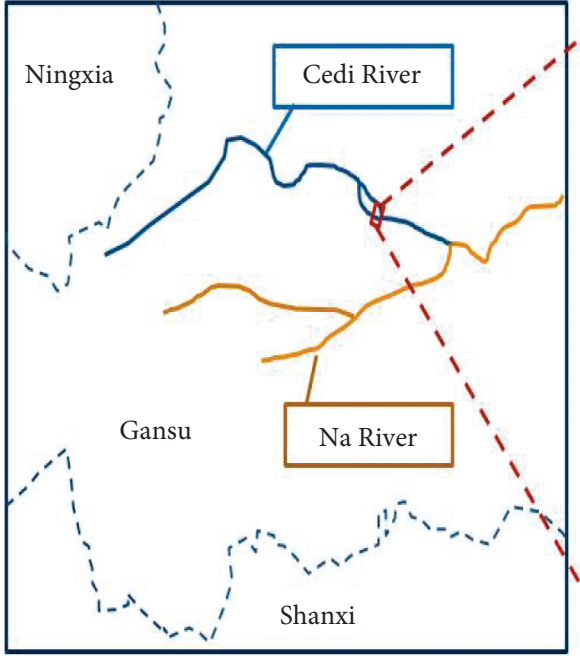

(a)

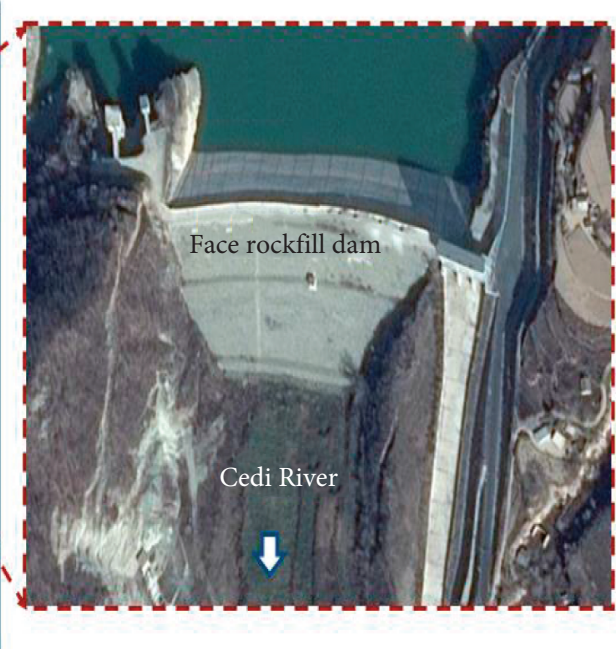

(b)

Figure 1: Shibaozhai CFRD on the Cedi River in Gansu Province, China.

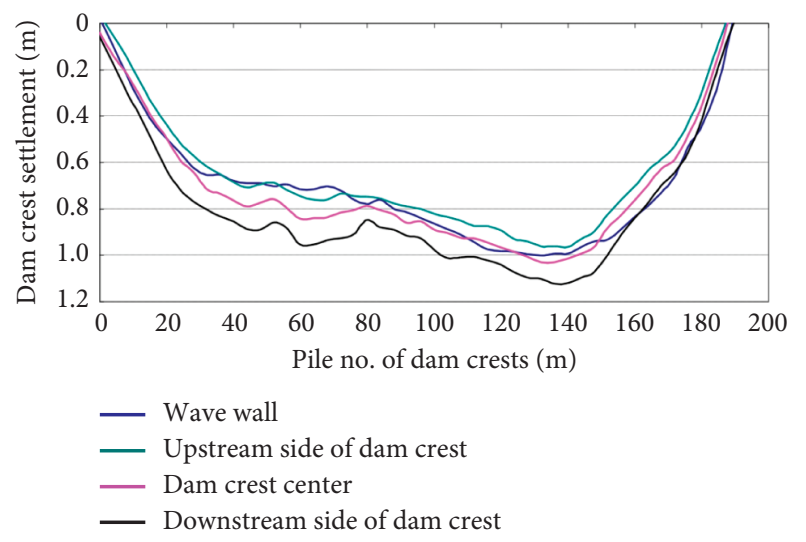

FIGURE 2: Measured settlement distribution of dam crest pavement and wave wall top.

of about $1.26 \mathrm{~m}$ below the ground and a horizontal distance of $1.9 \mathrm{~m}$ to the grouting hole. The SCM was bound well to the stones. Thus, the maximum horizontal diffusion radius of the mortar was up to $1.9 \mathrm{~m}$. The SCM flowed through the large pores and adhered to the surface of the rockfill. Mortar encapsulation and cementation took place at contact points between block stones, but the parts enriched with fine rockfill particles (gravelly soil) had small pore sizes, so the SCM could not enter to fill the pores.

Coring at the inspection hole indicated that the mortar cementation was evenly distributed in the core sample and accounted for about $31 \%$ of the total core length. At the same time, an in-hole TV camera was used to check the grouting effect. The depth of TV imaging in the hole was $5.0 \mathrm{~m}$, as shown in Figure 7. It can be seen that there were only a few large pores in the rockfill and most of the pores have been filled with SCM. In the inspection hole, 3019 type $\gamma$-ray density logging instrument was used, Co-60 was used as $\gamma$-ray source, the measurement range was $1.2 \mathrm{~m}$ in diameter, and the density and porosity of rockfill were measured. After grouting, the porosity of the rockfill was increased to $20.2 \%$, which achieved the expected effect of controllable grouting.

The permeability of the rockfill materials before and after grouting was obtained through an on-site water injection test. The results showed that the average permeability coefficients of the rockfill materials before and after grouting were calculated as 0.81 and $0.12 \mathrm{~cm} / \mathrm{s}$, respectively. Although the permeability of the rockfill materials after grouting was reduced to some extent, the rockfill materials were still capable of free drainage.

The on-site grouting reinforcement test of the CFRD showed that SCM was a feasible grouting material because it diffused in a controlled area around the grouting hole, filled the large pores, reduced the porosity, and developed a certain degree of cementation while still maintaining good water permeability in the rockfill materials.

\section{Mechanical Test of Grout-Reinforced Rockfill Materials}

4.1. Mechanical Testing Process. A mechanical testing scheme for grout-reinforced rockfill materials was used on rockfill materials of average gradation before and after grouting reinforcement to study the effect on the mechanical properties. A postgrouting mechanical test was also performed on rockfill materials with gradation levels at the lower and upper bounds of the gradation envelope. In total, four groups were tested. Each group was subjected to a static large triaxial shear test under confining pressures of 200, 300, 400 , and $600 \mathrm{kPa}$. The details of each sample group are presented in Table 1 . The scaled gradation of the test materials was achieved by employment of the similar gradation method $(n=2)$ and then the equalization method; the mass percentage of each particle size was given in Table 1. Test samples were prepared according to the average porosity of $30 \%$ measured in the field and the corresponding dry density of $1.94 \mathrm{t} / \mathrm{m}^{3}$. 


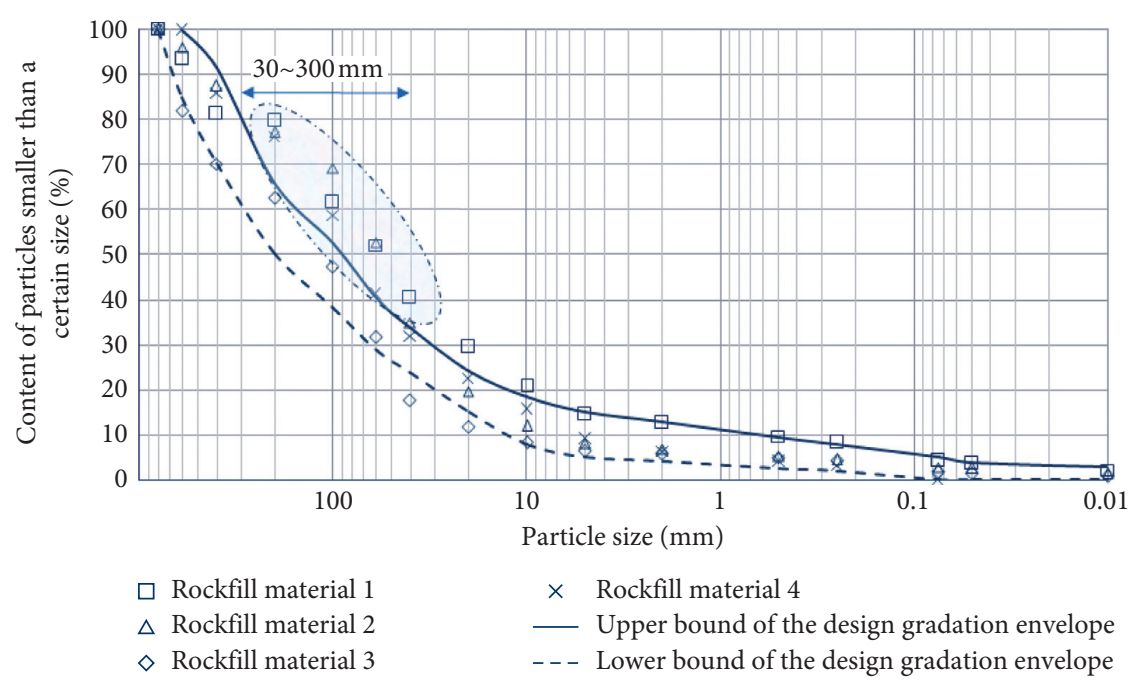

FIgURE 3: Results of the on-site screening test.

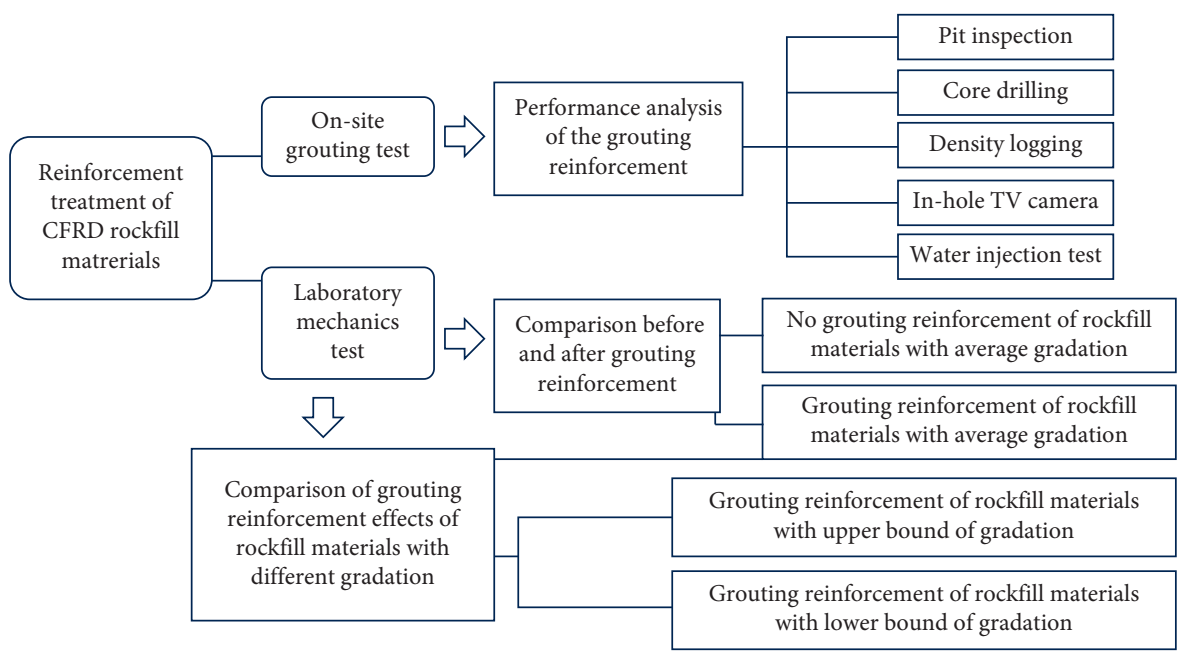

FIGURE 4: Test scheme of the grouting reinforcement treatment for CFRD rockfill materials.

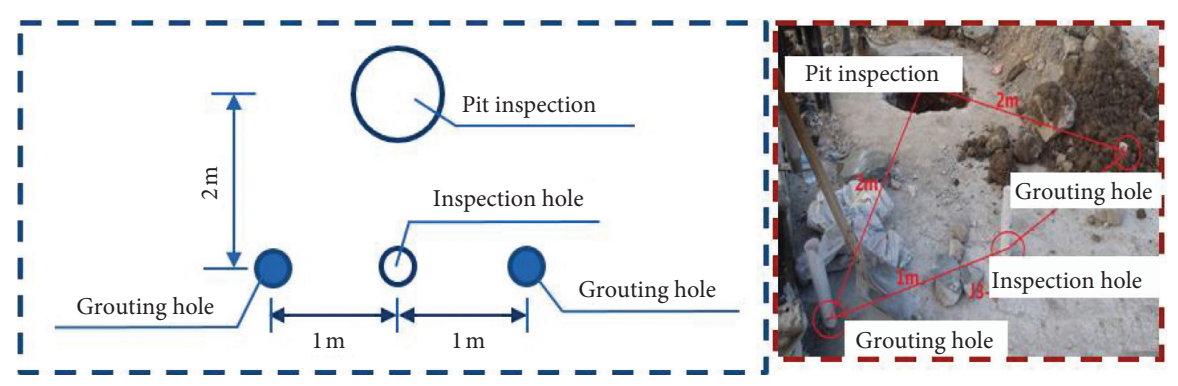

FIGURE 5: Setup of the on-site grouting reinforcement test.

The sample size was $\Phi 300 \mathrm{~mm} \times 700 \mathrm{~mm}$, and each sample was divided into five layers. Each layer was handled in three steps, as shown in Figure 8, sample loading, vibration compaction, and grouting consolidation:
(1) First, a single layer was weighed and stirred evenly in an iron pan; this was then placed in a sample preparation tank to ensure that the prepared sample was uniform. 


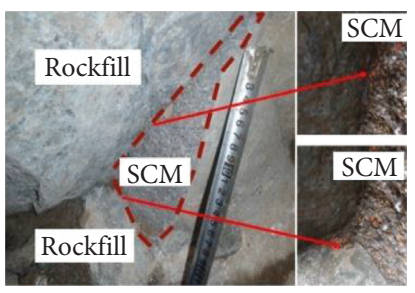

(a)

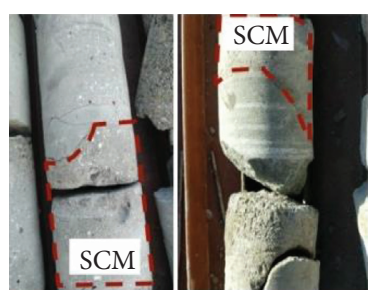

(b)
FIGURE 6: On-site pit inspection and core drilling inspection. (a) On-site pit inspection. (b) On-site core drilling inspection.
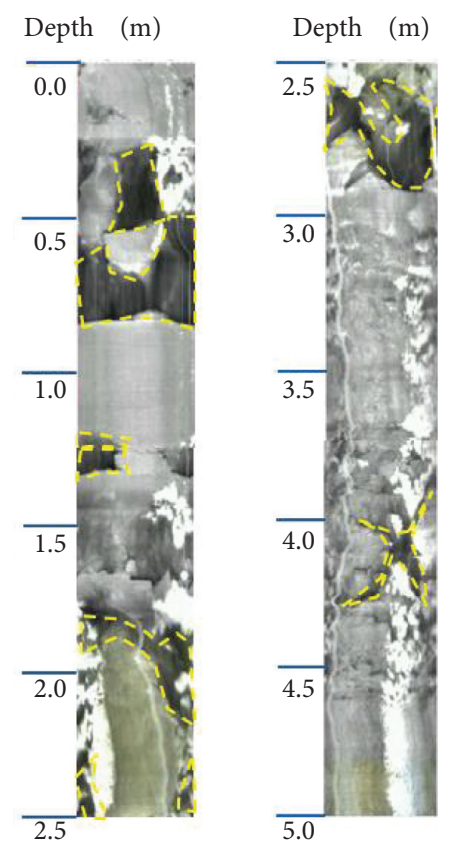

FIGURE 7: TV imaging in the inspection hole.

(2) For the mechanical vibratory compaction, the vibration time was controlled according to the required dry bulk density of the sample, while the porosity and dry density were controlled by the height of the single layer of rockfill materials.

(3) The mechanically vibrated rockfill body was grouted by even pouring of the mortar with good fluidity to the center of the rockfill body; the SCM accounted for $10 \%$ of the volume of each layer, which reduced the porosity of samples from $30 \%$ to $20 \%$. This process was repeated for each layer until the five layers were completely grouted. The grouted body was then allowed to stand still for 7 days of curing to ensure cementation. The indoor grouting test was set at a water-to-binder ratio of 1.15 , admixture percentage of $1 \%$, slump spread of $310 \mathrm{~mm}$, and $\mathrm{V}$-funnel time of $2.83 \mathrm{~s}$ for the SCM. The mortar test block showed a 7day compressive strength of $38.3 \mathrm{MPa}$.

The sample was saturated with the head saturation method. The axial load, deformation, and water displacement were recorded during the test. The test was carried out according to the Code for Coarse-grained Soil Tests for Hydropower and Water Conservancy Engineering (DL/ T5356-2006).

4.2. Mechanical Properties of the Rockfill Materials before and after Grouting Reinforcement. Figure 9 shows the stressstrain relationship curves of the rockfill materials with the average gradation in the triaxial shear test before and after grouting reinforcement. Before the grouting reinforcement, the rockfill materials showed obvious nonlinear characteristics of the strain-hardening type, which were consistent with the hyperbolic Duncan-Chang model. The stress-strain curves of the rockfill materials after grouting showed obvious peak strength and were of the strain-softening type. Because the stress level of the Shibaozhai CFRD was not high, the DuncanChang model can still be used to describe the curve characteristics before the peak value. Table 2 shows the strength parameters of the rockfill materials before and after grouting reinforcement and the Duncan-Chang model parameters.

The peak strength of the rockfill materials with average gradation was significantly improved with grouting reinforcement, which increased by $746,804,824$, and $793 \mathrm{kPa}$ after grouting reinforcement under confining pressures of $200,300,400$, and $600 \mathrm{kPa}$, respectively. It showed that the structural strength increased because of a certain degree of cementation between rockfill particles.

As the peak strength of the rockfill materials increased significantly after grouting, the linear cohesive force parameter $\mathrm{c}$ increased by $184.1 \mathrm{kPa}$, which is an increase of 3.95 times. The friction angle increased by $0.8^{\circ}$. This indicated that a cementitious structure formed between rockfill particles after grouting, which significantly improved the cohesive force of the rockfill materials. After grouting, the modulus (K) of the rockfill materials with average gradation was as high as 1506, which was 7.24 times higher than the modulus before grouting. This indicated that grouting significantly improved the deformation resistance of the rockfill materials.

\subsection{Mechanical Properties of the Rockfill Materials at Various} Gradation Levels after Grouting Reinforcement. Figure 10 shows the stress-strain relationship curves of rockfill materials with upper and lower bounds of gradation in the triaxial shear test after grouting. As indicated by the peak strength comparison between rockfill materials at different gradation levels after grouting, a higher content of coarse particles increased the effect of the coarse-grained framework structure and the peak strength of the rockfill materials. Thus, as the coarse grain content increased, the peak stress showed a significant increase.

As the coarse particle content increased, the mechanism of the shear dilation varied. The stress-strain curves of rockfill materials at the upper bound of gradation after grouting reinforcement were of the strain-hardening type. However, the postgrouting stress-strain curves of the rockfill materials with average and lower bound gradations exhibited obvious peak strength. This indicated a typical strain-softening type of relationship with a linear pattern after yielding. 
TABLE 1: Sequential numbers of mechanical test groups after grouting reinforcement and the mass percentages of particle size fractions at different gradation levels.

\begin{tabular}{|c|c|c|c|c|c|c|c|}
\hline \multirow{2}{*}{ Test no. } & \multirow{2}{*}{ Gradation characteristics } & \multirow{2}{*}{ Grouted or not } & \multicolumn{5}{|c|}{ Mass percentage of particle size fractions (\%) } \\
\hline & & & $60-40 \mathrm{~mm}$ & $40-20 \mathrm{~mm}$ & $20-10 \mathrm{~mm}$ & $10-5 \mathrm{~mm}$ & $5-0 \mathrm{~mm}$ \\
\hline 1 & Average & Not grouted & 17.2 & 39.2 & 18.6 & 11.3 & 13.7 \\
\hline 2 & Upper bound & Grouted & 16.6 & 35.6 & 16.4 & 13.1 & 18.3 \\
\hline 3 & Average & Grouted & 17.2 & 39.2 & 18.6 & 11.3 & 13.7 \\
\hline 4 & Lower bound & Grouted & 23.5 & 48.3 & 12.8 & 6.9 & 8.4 \\
\hline
\end{tabular}

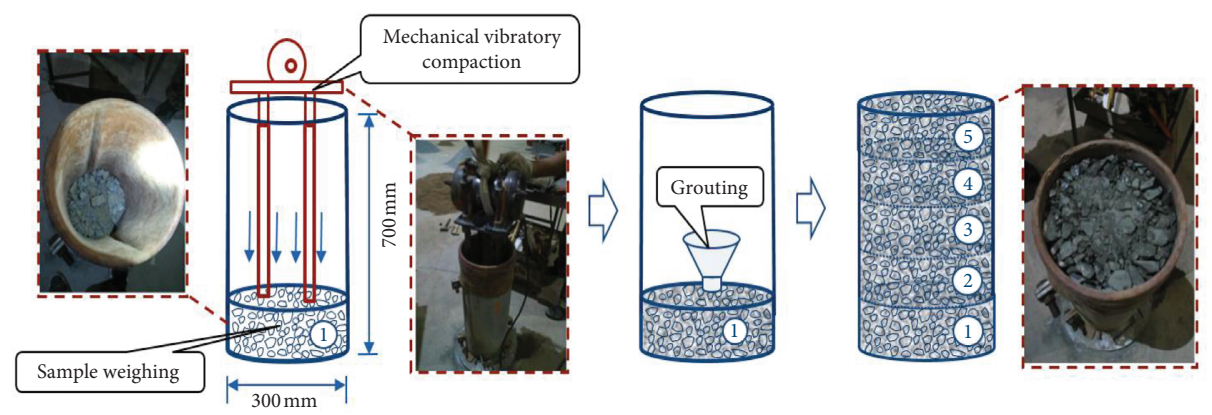

FIGURE 8: Preparation process of grout-reinforced samples of rockfill materials.

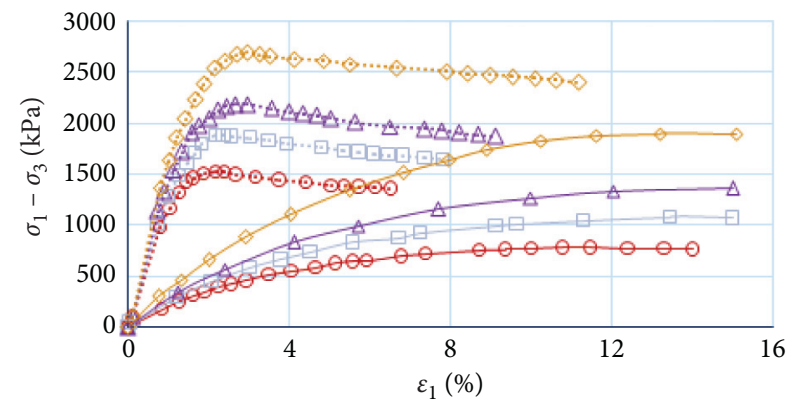

๑. Confining pressure $200 \mathrm{kPa}$ (grouted)

$\square$. Confining pressure $300 \mathrm{kPa}$ (grouted)

$\triangle$.. Confining pressure $400 \mathrm{kPa}$ (grouted)

$\diamond$. Confining pressure $600 \mathrm{kPa}$ (grouted)

- Confining pressure $200 \mathrm{kPa}$ (not grouted)

$\square-$ Confining pressure $300 \mathrm{kPa}$ (not grouted)

$\triangle$ Confining pressure $400 \mathrm{kPa}$ (not grouted)

$\diamond$ Confining pressure $600 \mathrm{kPa}$ (not grouted)

(a)

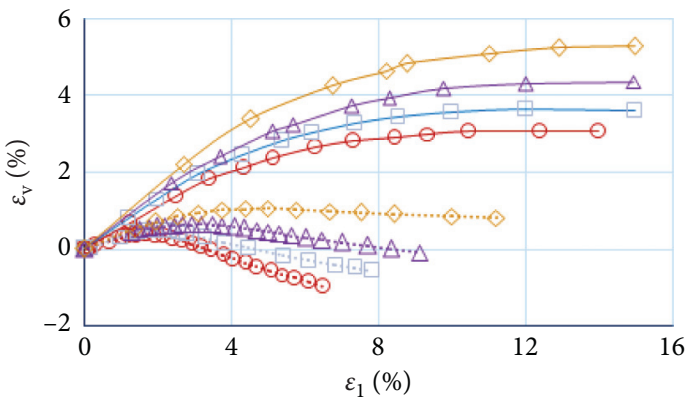

๑.. Confining pressure $200 \mathrm{kPa}$ (grouted)

- Confining pressure $300 \mathrm{kPa}$ (grouted)

$\triangle$.. Confining pressure $400 \mathrm{kPa}$ (grouted)

$\diamond$ Confining pressure $600 \mathrm{kPa}$ (grouted)

○-Confining pressure $200 \mathrm{kPa}$ (not grouted)

$\square$ Confining pressure $300 \mathrm{kPa}$ (not grouted)

$\triangle$ Confining pressure $400 \mathrm{kPa}$ (not grouted)

$\diamond$ Confining pressure $600 \mathrm{kPa}$ (not grouted)

(b)

Figure 9: Relationship curves of the deviatoric stress and body strain with the axial strain of rockfill materials with average gradation in the triaxial shear test before and after grouting reinforcement. (a) Deviatoric stress. (b) Body strain.

The upper bound gradation had a high content of fine particles, so the sample had a small equivalent pore size and contained a small number of channels that allowed the mortar to flow. The grouting process was dominated by the filling of pores and channels, while the cementitious structure did not have an obvious effect. The sample mainly experienced interparticle sliding, which resulted in shear dilation deformation. Therefore, the stress-strain curve still showed compressive hardening characteristics.

For average and lower bound gradations, the rockfill materials contained a high content of coarse particles, and the skeleton mainly comprised coarse aggregate. The samples had a large equivalent pore size between coarse aggregates and numerous channels which allowed the mortar to flow. There was a certain degree of cohesive strength between particles after grouting, thereby permitting the formation of a rather stable cementitious structure. This made interparticle sliding and displacement relatively difficult to take place, and the strain was dominated by plastic shear deformation. Thus, the stress-strain curves showed typical strain-softening characteristics.

Table 3 presents the strength parameters and main Duncan-Chang model parameters of the rockfill materials at different gradation levels after grouting. The linear cohesive 
TABLE 2: Strength parameters and Duncan-Chang model parameters of rockfill materials with average gradation before and after grouting reinforcement.

\begin{tabular}{|c|c|c|c|c|c|c|c|c|c|c|}
\hline \multirow[t]{2}{*}{$\begin{array}{l}\text { Test } \\
\text { no }\end{array}$} & \multirow[t]{2}{*}{$\begin{array}{c}\text { Gradation } \\
\text { characteristics }\end{array}$} & \multirow[t]{2}{*}{$\begin{array}{c}\text { Grouted or } \\
\text { not }\end{array}$} & \multicolumn{4}{|c|}{$\left(\sigma_{1}-\sigma_{3}\right) \max (\mathrm{kPa})$} & \multicolumn{2}{|c|}{$\begin{array}{l}\text { Linear } \\
\text { indicator }\end{array}$} & \multicolumn{2}{|c|}{$\begin{array}{c}\text { Duncan- } \\
\text { Chang } \\
\text { model } \\
\text { parameter }\end{array}$} \\
\hline & & & $\begin{array}{c}\text { Confining } \\
\text { pressure } 200 \mathrm{kPa}\end{array}$ & $\begin{array}{c}\text { Confining } \\
\text { pressure } 300 \mathrm{kPa}\end{array}$ & $\begin{array}{c}\text { Confining } \\
\text { pressure } 400 \mathrm{kPa}\end{array}$ & $\begin{array}{c}\text { Confining } \\
\text { pressure } 600 \mathrm{kPa}\end{array}$ & $\begin{array}{c}\mathrm{c} \\
(\mathrm{kPa})\end{array}$ & $\phi\left({ }^{\circ}\right)$ & K & $n$ \\
\hline 1 & Average & $\begin{array}{c}\text { Not } \\
\text { grouted }\end{array}$ & 781 & 1082 & 1362 & 1902 & 62.4 & 35.6 & 208 & 0.39 \\
\hline 3 & Average & Grouted & 1527 & 1886 & 2186 & 2695 & 246.5 & 36.4 & 1506 & 0.27 \\
\hline
\end{tabular}

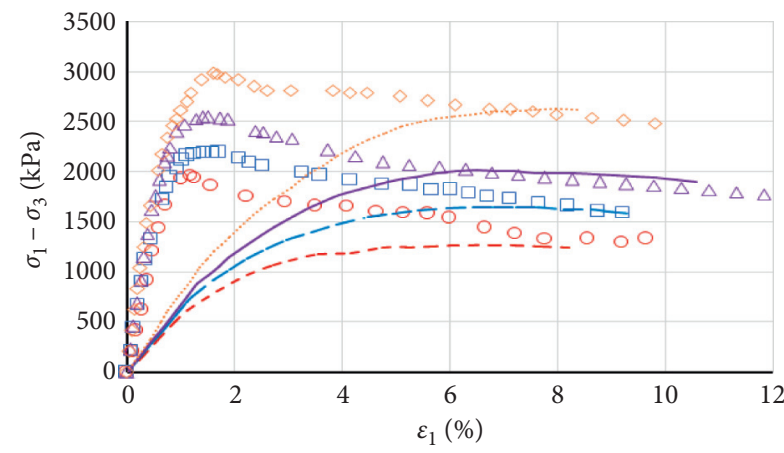

- Confining pressure $200 \mathrm{kPa}$ (lower bound)

$\square \quad$ Confining pressure $300 \mathrm{kPa}$ (lower bound)

$\triangle$ Confining pressure $400 \mathrm{kPa}$ (lower bound)

$\diamond$ Confining pressure $600 \mathrm{kPa}$ (lower bound)

- - - Confining pressure $200 \mathrm{kPa}$ (upper bound)

-. - Confining pressure $300 \mathrm{kPa}$ (upper bound)

_ Confining pressure $400 \mathrm{kPa}$ (upper bound)

Confining pressure $600 \mathrm{kPa}$ (upper bound)

(a)

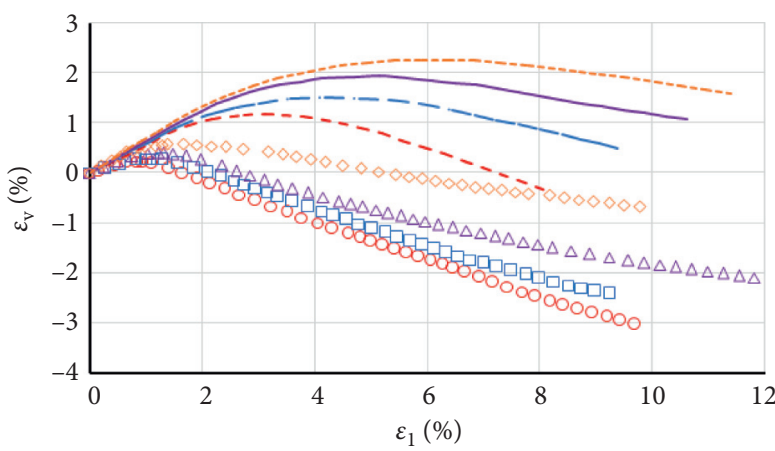

○ Confining pressure $200 \mathrm{kPa}$ (lower bound)

$\square \quad$ Confining pressure $300 \mathrm{kPa}$ (lower bound)

$\triangle$ Confining pressure $400 \mathrm{kPa}$ (lower bound)

$\diamond$ Confining pressure $600 \mathrm{kPa}$ (lower bound)

- - - Confining pressure $200 \mathrm{kPa}$ (upper bound)

..- Confining pressure $300 \mathrm{kPa}$ (upper bound)

_ Confining pressure $400 \mathrm{kPa}$ (upper bound)

Confining pressure $600 \mathrm{kPa}$ (upper bound)

(b)

Figure 10: Relationship curves of the deviatoric stress and body strain with the axial strain of rockfill materials with gradation at the upper and lower bound of the gradation envelope after grouting reinforcement. (a) Deviatoric stress for the upper bound and lower bound. (b) Body strain for upper bound and lower bound.

TABle 3: Strength parameters and Duncan-Chang model parameters of rockfill materials at different gradation levels after grouting.

\begin{tabular}{|c|c|c|c|c|c|c|c|c|c|c|}
\hline \multirow[t]{2}{*}{$\begin{array}{l}\text { Test } \\
\text { no }\end{array}$} & \multirow[t]{2}{*}{$\begin{array}{c}\text { Gradation } \\
\text { characteristics }\end{array}$} & \multirow[t]{2}{*}{$\begin{array}{c}\text { Grouted or } \\
\text { not }\end{array}$} & \multicolumn{4}{|c|}{$\left(\sigma_{1}-\sigma_{3}\right) \max (\mathrm{kPa})$} & \multicolumn{2}{|c|}{$\begin{array}{c}\text { Linear } \\
\text { indicator }\end{array}$} & \multicolumn{2}{|c|}{$\begin{array}{c}\text { Duncan- } \\
\text { Chang } \\
\text { model } \\
\text { parameter }\end{array}$} \\
\hline & & & $\begin{array}{c}\text { Confining } \\
\text { pressure } 200 \mathrm{kPa}\end{array}$ & $\begin{array}{c}\text { Confining } \\
\text { pressure } 300 \mathrm{kPa}\end{array}$ & $\begin{array}{c}\text { Confining } \\
\text { pressure } 400 \mathrm{kPa}\end{array}$ & $\begin{array}{c}\text { Confining } \\
\text { pressure } 600 \mathrm{kPa}\end{array}$ & $\begin{array}{c}c \\
(\mathrm{kPa})\end{array}$ & $\phi\left({ }^{\circ}\right)$ & $K$ & $n$ \\
\hline 2 & Upper bound & Grouted & 1271 & 1651 & 2021 & 2633 & 149.2 & 38.9 & 625 & 0.25 \\
\hline 3 & Average & Grouted & 1527 & 1886 & 2186 & 2695 & 246.5 & 36.4 & 1506 & 0.27 \\
\hline 4 & Lower bound & Grouted & 1973 & 2205 & 2546 & 2982 & 385.8 & 34.2 & 3320 & 0.3 \\
\hline
\end{tabular}

force parameter c significantly increased, while the friction angle decreased somewhat with increasing coarse particle content. This indicated that coarser particles improved the cementation effect on rockfill materials. After grouting, the modulus K was 625, 1506, and 3320 for the upper bound, average, and lower bound gradations, respectively. This indicated that coarser particle content increased the skeleton effect and deformation resistance after grouting. 


\section{Conclusion}

In this study, the feasibility of grouting with the SCM was verified by an on-site grouting reinforcement test, and indoor triaxial shear test was performed to evaluate the mechanical properties of rockfill materials before and after grouting. The following conclusions were drawn:

(1) The on-site grouting reinforcement test showed that SCM-based grouting reinforcement technology increased the compactness of the rockfill materials and degree of interparticle cementation while allowing a certain porosity and free drainage.

(2) The mechanical test showed that grouting reinforcement significantly improved the cohesive force of the rockfill materials, while the friction angle did not change significantly. This indicates that a cementitious structure was formed between rockfill particles. After grouting reinforcement, the modulus of the rockfill materials also increased significantly, which indicated that the deformation resistance greatly improved.

(3) The mechanical test showed that increasing the coarse particle content of the rockfill materials increased the skeleton effect, which made a stable cementitious structure more likely to form after grouting reinforcement. Thus, a better cementation effect would be achieved with a greater cohesive force and modulus.

(4) After grouting reinforcement, rockfill materials were less likely to undergo interparticle sliding and displacement but were dominated by plastic sliding; the stress-strain curve showed typical strain-softening characteristics.

Therefore, this technology met the reinforcement requirements of CFRD rockfill materials and could be applied for setting the high modulus zone of high CFRDs or reinforcement of dams at risk due to excessive deformation.

\section{Data Availability}

The data in this article are obtained from original field or laboratory tests with all the authors' help. Anyone who wants to use the data should acknowledge the provenance of the article and apply for permission from the authors if convenient.

\section{Conflicts of Interest}

The authors declare that they have no conflicts of interest.

\section{Acknowledgments}

This work was financially supported by the National Science Foundation of China (Grant nos. 51979218 and U1965107), the Key Laboratory of Geological Hazards on Three Gorges Reservoir Area (China Three Gorges University), Ministry of Education (no. 2017KDZ01), and the Basic Research
Program of Natural Science in Shaanxi Province (no. 2018JM5118).

\section{References}

[1] B. O. Hardin, "Crushing of soil particles," Journal of Geotechnical Engineering, vol. 111, no. 10, pp. 1177-1192, 1985.

[2] Z.-Y. Cai, X.-M. Li, L. Han, and Y.-F. Guan, "Critical state of rockfill materials considering particle gradation and breakage," Journal of Geotechnical Engineering, vol. 38, no. 8, pp. 1357-1364, 2016.

[3] Z. Yang and G. Jiang, "Deformation control of the $200 \mathrm{~m}$ high hongjiadu concrete faced rockfill dam," Modern Rockfill Dams, pp. 15-23, China Press, Kuala Lumpur, Malaysia, 2009.

[4] P. Johannesson, "Modified zoning and compaction requirements for future high CFRDs," in Proceedings of the Workshop on High Dam Know-how, pp. 237-257, Yichang, China, February 2007.

[5] P. T. Cruz, J. R. Freitas, and S. Manocl, "Cracks and flows in concrete face rock fill dams (CFRD)," in Proceedings of the 5th International Conference on Dam Engineering, pp. 1-14, Lisbon, Portugal, February 2007.

[6] J. A. Sobrinho, L. V. Xavier, S. C. Albertoni, and R.F. Pereira, "Performance and concrete face repair at campos novos," International Journal on Hydropower \& Dams, vol. 2, no. 2, pp. 39-42, 2007.

[7] Ze-ping Xu and G. Deng, "Study on stress and deformation characteristics of $300 \mathrm{~m}$ high concrete face rockfill dam. Safety study of high face rockfill dam and progress of soft rock dam construction technology," 2014.

[8] X. Niu, "Security of high concrete face rockfill dam consideration and conclusion," Journal of Hydroelectric Engineering, vol. 36, no. 1, pp. 104-111, 2017.

[9] X. Cai, J. Yang, X.-W. Guo, and Y.-L. Wu, "Elastoplastic constitutive model for cement-sand-gravel material," Chinese Journal of Geotechnical Engineering, vol. 38, no. 9, pp. 15691577, 2016.

[10] I. Nagayama, "Development of the CSG construction method for sediment trap dams," Civil Engineering Journal, vol. 41, no. 7, pp. 6-17, 1999.

[11] F. Zhang, X. Li, Y. Peng et al., "Analysis of stress and seepage control measures in the cement sand gravel dam," Journal of China Institute of Water Resources and Hydropower Research, vol. 13, no. 3, pp. 194-200, 2015.

[12] S. C. Nichols and D. J. Goodings, "Physical model testing of compaction grouting in cohesionless soil," Journal of Geotechnical and Geoenvironmental Engineering, vol. 126, no. 9, pp. 848-852, 2000.

[13] Z. Jingbo, C. Zhi-chao, and L. Xiao-bo, "Reinforcement mechanism of cement slurry grouting in collapsible loess," Journal of Architecture and Civil Engineering, vol. 34, no. 6, pp. 65-70, 2017.

[14] Z. Wang, L. I. Long, and C. Wang, "Experimental study on failure of cracked rock-like material after grouting reinforcement," Journal of Central South University (Science and Technology), vol. 49, no. 4, pp. 957-963, 2018.

[15] H. C. Wang, J. D. Xin, X. H. An, X. Q. Xu, and L. J. Zhou, "Study on the material mechanical performance of large scale self-compacting rock-filled concrete," Advanced Materials Research, vol. 482-484, pp. 1362-1367, 2012.

[16] X. An, Q. Wu, F. Jin et al., "Rock-filled concrete, the new norm of SCC in hydraulic engineering in China," Cement and Concrete Composites, vol. 54, pp. 89-99, 2014. 
[17] B. Benabed, E.-H. L. Kadri, and S. Kenai, "Properties of selfcompacting mortar made with various types of sand," Cement and Concrete Composites, vol. 34, no. 10, pp. 1167-1173, 2012.

[18] European Project Group, "Specification and guidelines for self-compacting concrete," 2002. 